\title{
Hyaluronic Acid Reduces Fibrosis in a Rabbit Model of Urethral Anastomosis
}

\author{
Eliseo Portilla-de Buen' \\ Juan Pablo Ramirez- \\ Contreras $^{2}$ \\ Jonathan Matias Chejfec- \\ Ciociano (1D ${ }^{2}$ \\ Rodrigo Lopez-Falcony ${ }^{3}$ \\ David Garcia-Martinez' \\ Jose Gonzalo Vazquez- \\ Camacho ${ }^{4}$ \\ Clotilde Fuentes-Orozco ${ }^{2}$ \\ Francisco Jose Barbosa- \\ Camacho (iD ${ }^{2}$ \\ Juan Carlos Ibarrola- \\ Peña (iD ${ }^{2}$ \\ Alejandro Gonzalez- \\ Ojeda (iD $)^{2}$
}

'Surgical Research Division, Western Biomedical Research Center, Western Medical Center, Mexican Institute of Social Security, Guadalajara, Jalisco, México; ${ }^{2}$ Biomedical Research Unit 02, Specialties Hospital, Western Medical Center, Mexican Institute of Social Security, Guadalajara, Jalisco, México; ${ }^{3}$ Guanajuato State Transplant Center, Institute of Public Health of Guanajuato, Guanajuato, México; ${ }^{4}$ Cellular Biology Laboratory, School of Medicine, Instituto Tecnológico de Estudios Superiores de Monterrey, Campus Guadalajara, Jal, México

Correspondence: Alejandro GonzalezOjeda

Instituto Mexicano del Seguro Social, Av. Belisario Domínguez \# 1000, Colonia Independencia, Guadalajara, 44340, Jalisco, México

Tel +52333I294I65

Email avygail5@gmail.com
Introduction: Urethral stricture caused by fibrosis is a common medical condition, but topline therapy for this pathology has a high recurrence rate. This study aimed to determine the efficacy of hyaluronic acid (HA) treatment in preventing the development of fibrosis in a rabbit model of urethral anastomosis.

Materials and Methods: This experimental study involved 20 rabbits. HA $(0.5 \mathrm{~mL}, 25 \mu \mathrm{g} /$ $\mathrm{mL})$ was applied in the experimental group $(\mathrm{n}=10)$ during an experimental urethral anastomosis, and sterile saline $(0.9 \%)$ solution was applied in the control group $(\mathrm{n}=10)$. Animals underwent reoperation 12 weeks later for urethral resection. Fibrosis, inflammation, and urethral diameter were measured by two blinded pathologists at the site of the anastomosis.

Results: The amount of inflammatory infiltrate was similar in both groups. The thicknesses of the collagen fiber band were $275.9 \pm 62.3$ and $373.4 \pm 44.3 \mu \mathrm{m}$ in the study and control groups $(p=0.001)$, respectively, and the urethral lumen diameters at the anastomosis site at follow-up were $2575 \pm 167$ and $2382 \pm 214 \mu \mathrm{m}$, respectively $(\mathrm{p}=0.04)$.

Conclusion: HA treatment reduced fibrosis at the anastomosis site during this experiment; we suggest further research to corroborate its efficacy in the treatment of urethral stricture. Keywords: hyaluronic acid, submucosal application, urethral anastomosis, urethral stricture, fibrosis

\section{Introduction}

Urethral stricture is defined as narrowing of the lumen caused by fibrosis or scarring of the urethral epithelium, and it can develop at any site. ${ }^{1}$ Patients might present with recurrent urinary tract infections and dysuria, which could eventually lead to obstructive renal failure. ${ }^{2,3}$ It has also been associated with a significant prevalence $(82.2 \%)$ of erectile dysfunction. ${ }^{4}$ The etiology of urethral stricture ranges from direct injuries to the lower urinary tree, such as the prolonged use of urinary catheters, transurethral resection of the prostate, and radical prostatectomy, to injuries from external trauma and infections. ${ }^{2,3,5}$

Currently, urethral dilation and internal urethrotomy are recommended as the first line of treatment in single strictures, with similar clinical efficacy. Although the success rate is high, studies report only $9 \%$ of success after 1 to 3 years of followup. ${ }^{6-8}$ Current treatments show a high percentage of failure due to the new epithelial lesion that is generated and the concentric fibrotic scarring that obliterates the lumen. Up to $16.7 \%$ of internal urethrotomies have a recurrence a year after treatment, and $25 \%$ of urethroplasties after 6 months. ${ }^{9,10}$ 
There is evidence of adjuvant urethrotomy treatments showing higher success rates compared with the success rate of isolated urethrotomy; for example, the application of mitomycin $\mathrm{C}$, triamcinolone, or captopril. However, this evidence comes from studies with little follow-up. ${ }^{11-14}$

The high incidence of recurrence after treatment for urethral strictures denotes the importance of further investigation.

The study of wound healing during the fetal stage has provided information that could lead to novel therapeutic strategies. There is evidence that wounds caused during the fetal stage go through a healing process lacking fibrotic tissue when compared with adults. ${ }^{15}$ This is believed to be mainly because of the presence of an extracellular matrix with different macromolecular structural components; in particular, the appearance of an environment rich in hyaluronic acid (HA) that facilitates cell motility, proliferation, and regeneration. ${ }^{16}$ It is thought that HA organizes the disposition of collagen and favors early cell proliferation in such a way that it does not cause tissue retraction. ${ }^{17,18}$

Based on these previous studies, we hypothesized that the application of HA would reduce the development of fibrosis and stricture in a rabbit model of urethral anastomosis.

\section{Materials and Methods}

Twenty male New Zealand White rabbits weighing $2.5-3.0 \mathrm{~kg}$ were used in this experiment. The rabbits were monitored by trained personnel who provided proper management in accordance with local standards on care and use of laboratory animals. They were accommodated in separate boxes, with $12 / 12 \mathrm{~h}$ light/dark cycles and heaters.

The rabbits were deprived of food $12 \mathrm{~h}$ prior to surgery and were allocated to two groups to yield 10 animals per group. They were anesthetized with $2 \%$ xylazine $(5 \mathrm{mg} /$ $\mathrm{kg}$ ), intramuscularly (i.m.), and after $10 \mathrm{~min}, 10 \%$ ketamine $(35 \mathrm{mg} / \mathrm{kg}$ i.m.) was administered. Enrofloxacin ( $5 \mathrm{mg} / \mathrm{kg}$ i.m.) was applied post-surgery. During surgery, an intravenous (i.v.) line was maintained with $0.9 \%$ saline $(10 \mathrm{~mL} / \mathrm{h}$ i.v. $)$ through the marginal ear vein. ${ }^{19}$ Both the first and second surgeries used the same anesthetic procedure.

\section{Surgical Technique}

We used standard urethrotomy under direct vision with an operating microscope at $3 \times$ magnification. The genitalia were prepared for incision by swabbing with iodopovidone. The penis was released by incising the perianal skin membrane between the ventral portion of the penis and the anus. The preputial glands were separated from the midline to expose the urethra.

The urethra was dissected in its ventral portion and dorsal plate, followed by a transverse cut covering all the walls. Endto-end anastomosis of the sectioned portions was performed with six 6-0 caliber polyglactin separate simple stitches. Before the end, a 7-Fr silastic urinary catheter $(2.3 \mathrm{~mm}$ in diameter), corresponding to the smallest diameter identified during measurement of the urethral lumen, was placed for urinary diversion. The catheter was fixed using $5-0$ polyglactin sutures $5 \mathrm{~mm}$ away from the meatus; $0.5 \mathrm{~mL}$ of hyaluronic acid sodium salt from Streptococcus equi $(25 \mu \mathrm{g} / \mathrm{mL}$, SigmaAldrich, St. Louis, Missouri) or $0.9 \%$ sterile saline (in control rabbits) was infiltrated at 12,3,6, and 9 o'clock corresponding to the anterior, posterior, left lateral, and right lateral quadrants, respectively. HA or sterile saline was only infiltrated once, right at the end of the surgery. The skin was closed with simple 4-0 nylon sutures. Finally, chloramphenicol ointment (10 mgrs./gr) was applied to the surgical wound.

During the postoperative period, ketoprofen $(3 \mathrm{mg} / \mathrm{kg}$ i. $\mathrm{m}$.) was administered immediately after surgery, $12 \mathrm{~h}$ later, and every $24 \mathrm{~h}$ thereafter with the rabbit immobilized. Enrofloxacin (5 mg/kg i.m.) was injected 12, 24, 36, and $48 \mathrm{~h}$ after surgery. A liquid diet was maintained on the day of surgery, and normal feeding with chow formula for rabbits was started the following day. The urinary catheter was removed 5 days after surgery, with the rabbit under xylazine sedation ( $3 \mathrm{mg} / \mathrm{kg}$, i.m.).

Surgical reintervention was carried out 12 weeks after the first surgery. The genitals were sterilized with iodopovidone. The skin between the ventral portion of the penis and the anus was again incised until reaching the anastomosis site to resect the penis completely. The removed tissue was fixed in $10 \%$ buffered formalin solution for further processing and histopathological analysis. After surgical intervention, samples were randomly allocated by drawing lots for pathologists evaluation.

\section{Data Collection and Processing}

Penile tissues were fixed in $10 \%$ neutral buffered formalin solution and embedded in paraffin. After routine tissue processing, 5- $\mu \mathrm{m}$-thick sections were obtained. They were stained with hematoxylin and eosin and Masson's trichrome. The evaluation was carried out by two blinded pathologists to the surgical intervention of each sample. The concordance 
between the two observers was evaluated through the kappa coefficient of agreement test with a value of 0.9. Analysis was both macroscopic and microscopic (10, 20 and 40x). For histological comparison purposes, four rabbit urethral tissue samples were used without any surgical intervention. Qualitative variables were defined as the appearance and integrity of the epithelial intraluminal circumference at the anastomosis site compared with control samples. The epithelium was classified as regular, irregular, or very irregular. At $40 \times$ magnification, the infiltration of three different cell types was evaluated-polymorphonuclear cells, macrophages, and lymphocytes in the inflammatory infiltratewith scores given according to the percentage seen: 0 for no infiltration, + for $1-25 \%,++$ for $26-50 \%$, and +++ for equal or higher than $51 \%$. Foreign body reaction was classed as absent or present depending on the presence of giant cell infiltrates. The thickness of fibrosis in the anastomosis was measured in microns $(\mu \mathrm{m})$ using $40 \times$ magnification in all samples and the urethral diameters were measured using the software ImageJ $1.45 \mathrm{~s}$.

\section{Statistical Analysis}

Descriptive variables were recorded using raw numbers, proportions, means, and standard deviations. Qualitative variables were compared using Fisher's exact test. For ordinal qualitative variables, the Kruskal-Wallis test was used. Quantitative variables were analyzed using Student's $t$-test for independent samples after determining the equality of variances with the Levene's test; $\mathrm{p}<0.05$ was considered statistically significant. Excel for Windows (version 2007; Microsoft, Redmond, WA, USA) and IBM SPSS Statistics for Windows (version 20; IBM Corp., Armonk, NY, USA) were used in the analysis.

\section{Results}

The arrangement of collagen fibers was analyzed microscopically. All animals in the control group showed fibrosis throughout the perimeter of the anastomosis compared with the experimental group, in which fibrosis was classified as mild or mild focal. The difference was statistically significant $(p=0.000)$. Epithelialization was classified as regular when it covered most of the circumference of the anastomosis and as normal when it did so completely. Most $(80 \%)$ of the specimens in both groups had regular epithelium.

The results are presented in Table 1. Immune cell invasions were similar in both groups with a low presence of macrophages and lymphocytes $(p=0.32)$. A foreign body reaction was found in $80 \%$ of the treated group and $70 \%$ of the control one $(p=0.60)$. The thickness of the collagen fiber layer was significantly less in the treated than in the control group $(\mathrm{p}=0.001)$. Urethral lumen diameters at the anastomosis site were significantly greater $(p=0.04)$ in the treated than in the control group, as shown in Figures 1 and 2.

Table I Results of the Macroscopic and Microscopic Evaluations of the Rabbit Penile Urethra in HA-Treated and Control Groups

\begin{tabular}{|c|c|c|c|c|c|}
\hline \multicolumn{2}{|l|}{ Variables } & \multirow{3}{*}{$\begin{array}{c}\text { Control }(n=10) \\
8 \\
2\end{array}$} & \multirow{3}{*}{$\begin{array}{c}\text { Experimental }(n=10) \\
8 \\
2\end{array}$} & \multirow{3}{*}{$\frac{\text { p value }}{* 0.70}$} & \multirow{3}{*}{$\begin{array}{l}95 \% \mathrm{Cl} \\
0.33-3\end{array}$} \\
\hline Epithelium & Regular & & & & \\
\hline & Normal & & & & \\
\hline \multirow[t]{3}{*}{ Inflammation } & No & 3 & 4 & $* 0.32$ & NC \\
\hline & Focal & 5 & 6 & & \\
\hline & Regular & 2 & 0 & & \\
\hline \multirow[t]{2}{*}{ Presence of macrophages in inflammatory infiltrate } & Absent & 9 & 8 & $* * 0.52$ & $0.27-1.8$ \\
\hline & Focal & 1 & 2 & & \\
\hline \multirow[t]{2}{*}{ Presence of lymphocytes in inflammatory infiltrate } & Absent & 7 & 5 & $* * 0.36$ & $0.56-4.29$ \\
\hline & Focal & 3 & 5 & & \\
\hline \multirow[t]{2}{*}{ Foreign body reaction } & Absent & 8 & 7 & $* * 0.60$ & $0.31-1.9$ \\
\hline & Focal & 2 & 3 & & \\
\hline \multicolumn{2}{|l|}{ Urethral diameter 12 weeks after anastomosis $(\mu \mathrm{m})$} & $2382 \pm 214$ & $2575 \pm 167$ & $* * * 0.04$ & $65-298.7$ \\
\hline \multicolumn{2}{|c|}{ Thickness of the collagen layer at the anastomosis site $(\mu \mathrm{m})$} & $373.4 \pm 44$ & $275.9 \pm 62$ & $* * * 0.001$ & $55-113.5$ \\
\hline
\end{tabular}

Notes: *Kruskal-Wallis test. **Fisher's exact test, *** Student's t-test.

Abbreviation: NC, no calculable. 


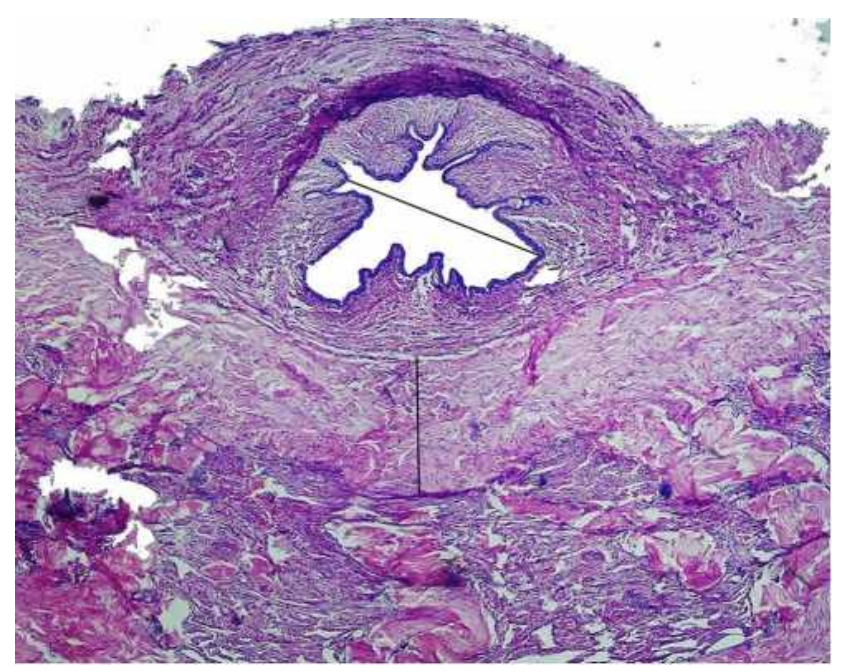

Figure I Representative control cross section (20x). The maximum diameter of the lumen was $2350 \mu \mathrm{m}$ and the collagen fiber layer was 35I $\mu \mathrm{m}$ thick. Mild to moderate inflammatory infiltration and poor neovascular formation is seen.

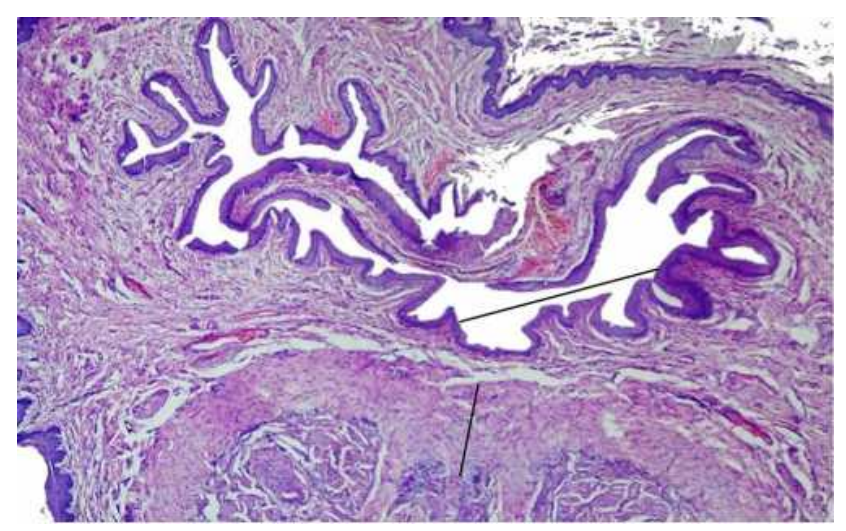

Figure 2 Representative study group cross section (20x). The maximum diameter of the lumen was $2670 \mu \mathrm{m}$ and the thickness of the collagen fiber band was $290 \mu \mathrm{m}$. Mild inflammatory infiltrates and moderate neovascular formation are evident.

\section{Discussion/Conclusions}

The group treated with hyaluronic acid showed significant reduction in the thickness of the fibrosis band, as well as an increase in the ureteral diameter where the first surgery was performed, demonstrating positive results in the adjuvant use of this macromolecule.

Kilinc et $\mathrm{al}^{20}$ demonstrated through a similar methodology on urethral injury in a rat model, the effect of intraurethral erythropoietin with results improving wound healing and preventing spongiofibrosis. Modifying the extracellular matrix by creating a more fetal-like environment could change the healing process in adults. ${ }^{21}$ Adan-Pimentel et $\mathrm{al}^{22}$ demonstrated in a canine model that the application of HA in a posterior urethral anastomosis produced less than $25 \%$ of stenosis compared with $45-65 \%$ in the control group.
Italiano et $\mathrm{al}^{23}$ demonstrated preservation of the urethral lumen with adequate compliance by resecting the urethra and replacing a segment with biodegradable hyaluronatebased grafts. Yildizhan et $\mathrm{al}^{24}$ evaluated the effect of HA on traumatic wounds to the urethra of 40 male Wistar rats. The results were not statistically significant, probably because of the short evaluation time, but a significant increase in tissue thickness was observed in the control group treated with saline. In a clinical setting, Chung et al ${ }^{25}$ reported the results of a controlled clinical trial involving 101 patients who underwent treatment of urethral stricture with internal urethrotomy with instillation of a combination of HA and carboxymethyl cellulose. The recurrence rate was $9 \%$ in the study group versus $23 \%$ in the untreated group $(\mathrm{p}<0.05)$.

In our literature review, we found no evidence regarding the intralesional application of HA in humans with urethral stricture; however, some evidence in experimental models suggests a beneficial therapeutic effect. ${ }^{22,26}$ Multiple techniques, such as tissue replacement with grafts and protein therapy, have been found to be effective in animal trials. ${ }^{27-30}$

Urethral stricture occurs because of excessive fibrosis in response to inflammation, tissue injury, and necrosis. In our study design, surgical trauma and inflammation played an important role in stenosis, because they precede collagen deposition, which will lead to stricture without effective healing. ${ }^{3,6,7}$ Based on this study, HA was associated with decreased inflammation and fibrosis during urethral trauma when compared to saline, reducing post-traumatic stenosis.

This study had several limitations. First, this was not a model of human urethral stricture, so future studies should address this issue in clinical settings. Second, data collection was limited to morphological and histochemical analysis, and collagen content and types were not evaluated. The intention of our protocol was not to recreate stricture, but rather to evaluate the healing process in an HA-rich environment. Therefore, it will be necessary further research to test the utility of this macromolecule in human clinical settings.

\section{Statement of Ethics}

The protocol was approved by the Local Research and Ethics Committee of the Biomedical Research Center of the West, Mexican Institute of Social Security with the register R-2007-1305-14. All animals were managed in accordance with the Official Mexican Standard Norm NOM-062-ZOO-1999 regarding the care and use of laboratory animals. ${ }^{31}$ The rabbits were monitored by trained personnel who provided proper management. 
They were accommodated in separate boxes, with $12 / 12$ h light/dark cycles and heaters.

\section{Acknowledgments}

We acknowledge pathologist José Gonzalo VazquezHuerta from ITESM campus Guadalajara for his support in the double blind histological analysis. We thank the professional editing service Online English for reviewing the manuscript for language, structure, and expression of ideas suitable for publication in the biomedical literature.

\section{Author Contributions}

EPdB, JPRC, JMChC, RLF \& DGM: were involved in the protocol design, surgical interventions, data collection, and manuscript writing. JGVC, CFO, JFBC, JCIP \& AGO: were involved in the protocol development, data collection, and manuscript editing. All authors made substantial contributions to conception and design, acquisition of data, or analysis and interpretation of data; took part in drafting the article or revising it critically for important intellectual content; agreed to submit to the current journal; gave final approval of the version to be published; and agree to be accountable for all aspects of the work.

\section{Funding}

This study was supported by research funding from the Health Research Coordination of the Mexican Institute of Social Security.

\section{Disclosure}

The authors of the protocol declare that they have no conflicts of interest and no financial conflicts whatsoever for the development of the project and the dissemination of its results.

\section{References}

1. Chung JH, Kang DH, Choi HY, et al. The effects of hyaluronic acid and carboxymethyl cellulose in preventing recurrence of urethral stricture after endoscopic internal urethrotomy: a multicenter, randomized controlled, single-blinded study. J Endourol. 2013;27:756-762. doi:10.1089/end.2012.0613

2. Singh M, Scott TM. The ultrastructure of human male urethral stricture. $\quad B r \quad J \quad$ Urol. 1975;47(7):871-876. doi:10.1111/j.1464410X.1975.tb04070.x

3. Singh M, Blandy JP. The pathology of urethral stricture. $J$ Urol. 1976;115:673-676. doi:10.1016/S0022-5347(17)59331-3

4. Mondal S, Bandyopadhyay A, Mandal MM, Pal DK. Erectile dysfunction in anterior urethral strictures after urethroplasty with reference to vascular parameters. Med J Armed Forces India. 2016;72(4):344-349. doi:10.1016/j.mjafi.2016.07.001
5. Lozano JL, Arruza A. Postoperative complications in 182 urethroplasties. Rev Mex Urol. 2014;74:68-73.

6. Gallegos M, Santucci R. Advances in urethral stricture management. F1000 Faculty Rev. 2016;5:1-9.

7. Hillary CJ, Osman NI, Chapple CR. Current trends in urethral stricture management. Asian J Urol. 2014;1:46-54. doi:10.1016/j. ajur.2015.04.005

8. Buckley JC, Heyns C, Gilling P, Carney J. SIU/ICUD consultation on urethral strictures: dilation, internal urethrotomy, and stenting of male anterior urethral strictures. Urology. 2014;83:18-22. doi:10.1016/j. urology.2013.08.075

9. Ofoha CG, Ramyil VM, Dakum NK, et al. Predictors of urethral stricture recurrence following urethroplasty: a retrospective review at the Jos University Teaching Hospital, Nigeria. Pan Afr Med J. 2019;32:190. doi:10.11604/pamj.2019.32.190.18 504

10. Ishigooka M, Tomaru M, Hashimoto T, Sasagawa I, Nakada T, Mitobe K. Recurrence of urethral stricture after single internal urethrotomy. Int Urol Nephrol. 1995;27(1):101-106. doi:10.1007/ BF02575227

11. Shirazi M, Khezri A, Samani SM, Monabbati A, Kojoori J, Hassanpour A. Effect of intraurethral captopril gel on the recurrence of urethral stricture after direct vision internal urethrotomy: phase II clinical trial. Int $J$ Urol. 2007;14:203-208. doi:10.1111/j.14422042.2007.01693.x

12. Mazdak H, Izadpanahi MH, Ghalamkari A, et al. Internal urethrotomy and intraurethral submucosal injection of triamcinolone in short bulbar urethral strictures. Int Urol Nephrol. 2010;42:565-568. doi:10.1007/s11255-009-9663-5

13. Tavakkoli K, Yarmohamadi A, Mohammadi S. Triamcinolone injection following internal urethrotomy for treatment of urethral stricture. Urol J. 2011;8:132-136.

14. Moradi M, Derakhshandeh K, Karimian B, Fasihi M. Safety and efficacy of intraurethral mitomycin $\mathrm{C}$ hydrogel for prevention of post-traumatic anterior urethral stricture recurrence after internal urethrotomy. $J$ Inj Violence Res. 2016;8:75-79. doi:10.5249/jivr.v8i2.812

15. Longaker M. Studies in fetal wound healing: v. A prolonged presence of hyaluronic acid characterizes fetal wound fluid. Ann Surg. 1991;213:292-296. doi:10.1097/00000658-199104000-00003

16. De Palma R, Krummel TM, Durham LA. Characterization and quantitation of wound matrix in the fetal rabbit. Matrix. 1989;9 (3):224-231. doi:10.1016/S0934-8832(89)80054-X

17. Harrison M, Adzick NS. The fetus as a patient surgical considerations. Ann Surg. 1991;213(4):279-291. doi:10.1097/ 00000658-199104000-00002

18. Dostal G, Gamelli RL. Fetal wound healing. Surg Gynecol Obstet. 1993;176(3):299-306.

19. Bimonte-Patetta D, Rodríguez-Nieves C, Casas L, VedovattiManzoni E. General anaesthesia in rabbit. REDVET. Revista electrónica de Veterinaria. 2007; VIII:1695-7504.

20. Kilinc MF, Doluoglu OG, Eser PE, et al. Intraurethral erythropoietin to prevent fibrosis and improve urethral healing: an Experimental Study in a rat model. Urology. 2019;123:297.e9-297.e14. doi:10.1016/j.urology.2018.05.045

21. Goa K, Benfield P. Hyaluronic acid. Drugs. 1994;43:536-566. doi:10.2165/00003495-199447030-00009

22. Adan-Pimentel A, Hernández-Aguilar G, Landa-Juárez S. Effects of hyaluronic acid on the healing mechanism in the urethra anastomosis. An experimental study. Bol Coleg Mex Urol. 2002;17:26-31.

23. Italiano G, Abatangelo G Jr, Calabrò A, et al. Reconstructive surgery of the urethra: a pilot study in the rabbit on the use of hyaluronan benzyl ester (Hyaff-11) biodegradable grafts. Urol Res. 1997;25:137-142. doi:10.1007/BF01037930

24. Yıldızhan M, Dundar M, Demirci B, Çulhacı N. The effects of hyaluronic acid on traumatic urethral inflammation. Urol Int. 2020;104(3-4):283-286. doi:10.1159/000504766 
25. Chung JH, Kang DH, Moon HS, et al. Effects of hyaluronic acid and carboxymethylcellulose on urethral stricture after transurethral resections of the prostate for benign prostatic hyperplasia: a multicenter, single blinded, randomized controlled study. $J$ Endourol. 2013;27:463-469. doi:10.1089/end.2012.0377

26. Hong JH, Choe JW, Kwon GY, et al. The effects of barrier materials on reduction of pericardial adhesion formation in rabbits: a comparative study of a hyaluronan-based solution and a temperature sensitive poloxamer solution/gel material. J Surg Res. 2011;166:206-213. doi:10.1016/j.jss.2010.09.034

27. Liu Y, Ma W, Liu B, et al. Urethral reconstruction with autologous urine-derived stem cells seeded in three-dimensional porous small intestinal submucosa in a rabbit model. Stem Cell Res Ther. 2017;8:63. doi:10.1186/s13287-017-0500-y

28. Žiaran S, Galambošová M, Danišovič L. Tissue engineering of urethra: systematic review of recent literature. Exp Biol Med (Maywood. 2017;1:1-14.
29. Bladair H, Liu TT, Kaar JL, et al. Matrix metalloproteinase-1 improves muscle healing. J Appl Physiol. 2007;102:2338-2345. doi:10.1152/japplphysiol.00670.2006

30. Guzmán-Esquivel J, Delgado-Enciso I, Baltazar-Rodríguez LM, Rodríguez-Hernández A, Juárez-Pineda $\mathrm{U}$, Melnikov $\mathrm{V}$. Metalloproteinase-1 usefulness in urethral stricture treatment. Int Urol Nephrol. 2011;43:763-769. doi:10.1007/s11255-011-9909-x

31. NORMA Oficial Mexicana NOM-062-ZOO-1999 [Internet]. Especificaciones técnicas para la producción, cuidado y uso de los animales de laboratorio. [cited November 1, 2017]. Available from: http://www.fmvz.unam.mx/fmvz/principal/archivos/062ZOO.pdf. Accessed April 28, 2021.

\section{Publish your work in this journal}

Research and Reports in Urology is an international, peer-reviewed, open access journal publishing original research, reports, editorials, reviews and commentaries on all aspects of adult and pediatric urology in the clinic and laboratory including the following topics: Pathology, pathophysiology of urological disease; Investigation and treatment of urological disease; Pharmacology of drugs used for the treatment of urological disease. The manuscript management system is completely online and includes a very quick and fair peer-review system, which is all easy to use. Visit http://www.dovepress.com/ testimonials.php to read real quotes from published authors. 